\title{
Anthropometric Study of External Ear: A Comparative Study in Medical Students of Nepalgunj Medical College in Nepal
}

\author{
Gupta $\mathrm{AK}^{1}$, Ambekar $\mathrm{MN}^{2}$
}

\begin{abstract}
Background: Anthropometry is the measurements of the body parts in the living or dead persons with the help of instruments. Many studies in the past are done for various purposes such as: adding data to statistical data bank, to estimate stature, age differences. The study on the measurement of ear is also helpful to forensic expert for individual identity, to cosmetic surgeon to correct shape and size or reconstruct the auricle, to electronic companies to prepare hearing aids and lastly to prosthetic makers who required average measurement of the auricle to prepare prosthesis. Aim and objective of the study: The aim of the study was to determine the normal anthropometric measurement of external ear in male and female Nepalese and Indian medical students. Material and methods: This study was conducted on 200 medical students (Nepalese students 134 and Indian student 66). The study was conducted during October 2017 to November 2017. All the important parameters were obtained using vernier caliper. Results: In Indian male auricular height and lobular height was found more than Nepalese. Auricular width was equal in both. Lobular width was more in left auricle and equal in right auricle in female. All parameters are more in Indian than Nepalese. Conclusion: These measurements are helpful for forensic expert in individual identity, for cosmetic surgeries, correction of anomalies of auricle, for designing hearing aids and prepare prosthesis.
\end{abstract}

Key words: Anthropometry, auricle, lobule, auricular height, auricular width, lobular height and width

\section{INTRODUCTION}

Anthropometric study refers to the measurement of the body parts with the help of instruments. Here it refers to the dimensions of external ear, mainly the height and the width in male and female medical students. External ears consist of the auricle or pinna and the external acoustic meatus ${ }^{1}$. This study was specifically under taken to study the variations in the auricle dimensions, specially height and width, amongst Nepalese and Indian medical students and compare them.

Greater part of the auricle is made up of a core of crumpled plate of elastic cartilage and hence it is irregular. It consists of outer rim called as a helix, parallel to the helix and interiorly is antihelix which encircles the deep depression called concha of auricle. Below the crus of helix is a conical projection called tragus which is separated from antitragus by intertragic notch. Below this is the soft lobule composed of fibro fatty tissue. The shape and the size of the auricle shows variations in reference to the sex and two side of same individuals, age and race ${ }^{1}$.

Auricle is defining feature of the face and gives aesthetic appearance to the face. So, its measurement data is useful to the forensic study in various races as well as in identifying the

1. Dr. Anil Kumar Gupta

2. Prof. M. N. Ambekar

Address for correspondence:

Dr. Anil Kumar Gupta

Department of Anatomy

Nepalgunj Medical College Teaching Hospital

Chisapani, Banke, Nepal

E-mail: dr.anilkugupta@gmail.com individuals. Data is also useful to cosmetic surgeons for otoplastic procedures².

From the past studies on anthropometric measurements of auricle the general statement can be made regarding the size, shape and ethnic variation as follows:

- Size varies according to the sex, age and the ethnic groups.

- The height of the auricle is more in male than in female.

- As the age advancs the size of auricle also increases.

There is definite difference in the size of the auricle in different races $^{3}$.

\section{MATERIAL AND METHODS}

This study was conducted on medical students studying in Nepalgunj Medical College, Chisapani, District Banke, Nepal. The total numbers of student were 200, with age group from 18 years to 24 years, out of this 66 were Indian student (male- 43 and female-26) and 134 were Nepalese students (male-85 and female-46). All the parameters were taken in the department of anatomy with the head in Frankfort horizontal plane. Those student having congenital auricular abnormalities, tumor, previous surgical history were excluded from this study. This study was done only in normal student.

Before starting the work, clearance of institutional ethical committee was taken. The purpose of the study was explained to all the subjects. Bilateral size (height and width) of the auricle and the lobule were measured in $\mathrm{mms}$ using vernier caliper. Standardized method and the points of measurements were as per description of De Carlo et $\mathrm{al}^{4}$ and Mc Kinney et $\mathrm{al}^{5}$ and Brucker et al ${ }^{6}$. 


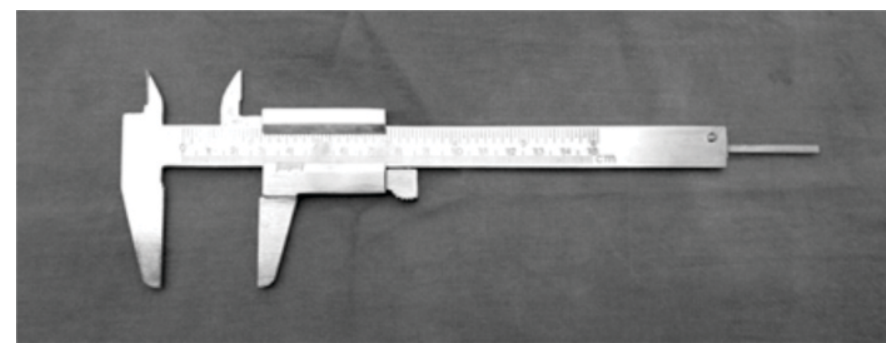

Figure 1: Vernier caliper

The measurements taken were:

- $\quad$ Auricle height $(\mathrm{AH})$ from point $\mathrm{A}-\mathrm{B}$

- $\quad$ Auricle width (AW) from point C-D

- $\quad$ Lobular height (LH) from point E-B

- $\quad$ Lobular width (LW) from point F-G

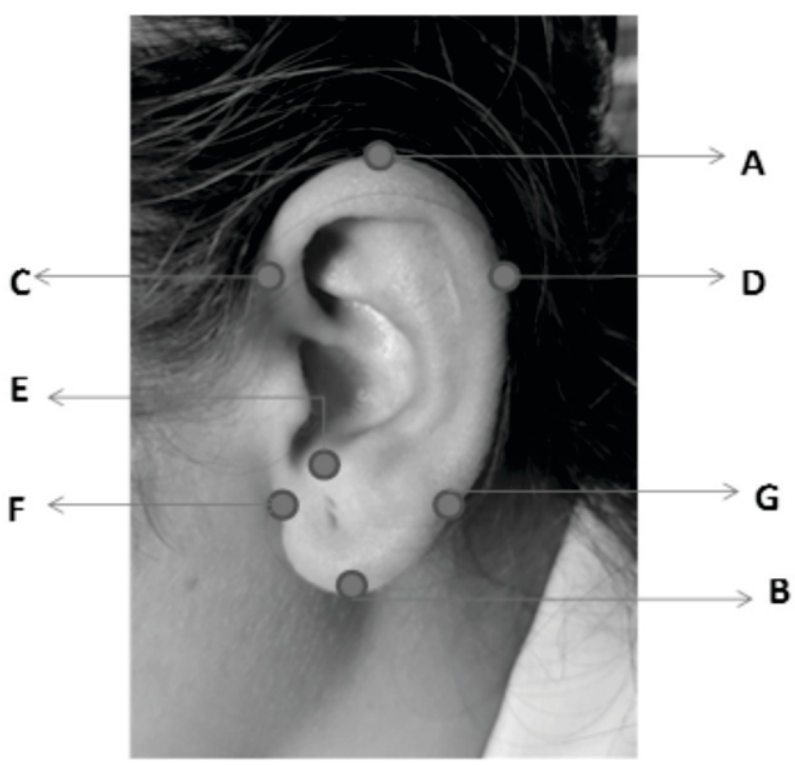

Figure: 2: Various points on auricle

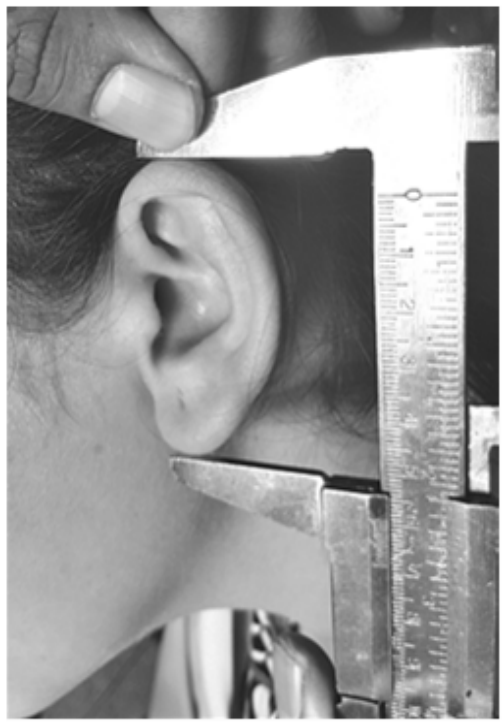

Figure: 3: Measuring the height of auricle

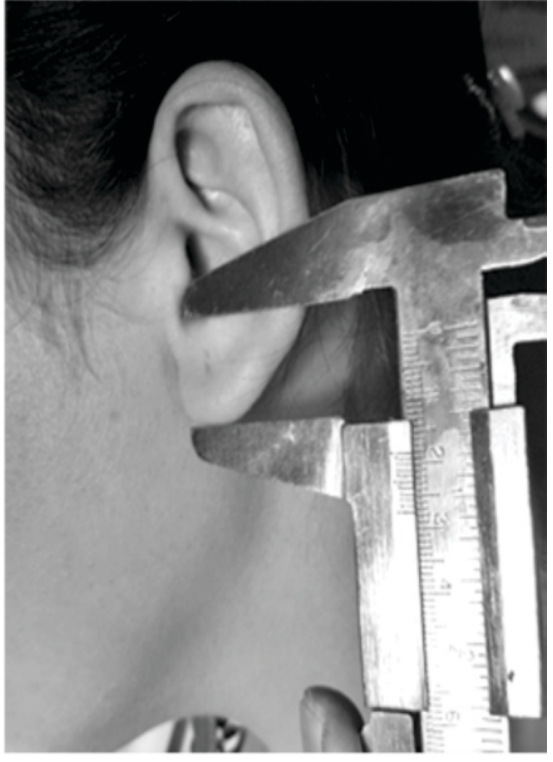

Figure: 4: Measuring the height of lobule

The auricle height was measured in $\mathrm{mm}$ as distance from highest point on Helix (A) to the lowest point on lobule at (B). Auricle width was measured as the distance from (C), the most anterior and (D) most posterior point of the auricle. Lobular height was measured as a distance from point (E) on intertragic notch to lower point on lobule (B). Lobular width was measured as distance from point $(F)$ to $(G)$

Figure 1 shows the instrument used and Figure 2 the point from which various measurements were taken. Figure 3 and 4 shows actual measurements being taken. The data collected was analyzed using a Statistical Package for Social Sciences version (SPSS) 20.0.

\section{RESULT}

The measurement of various parameters of auricle according to sex and ethnic group Nepalese and Indian is shown in Table I and Table II.

In male (Nepalese and Indians): Auricular height and lobular height in Indian male student was found more than the Nepalese male students on both right and left side. Auricular width is equal on both Nepalese and Indian male students. But the lobular width was more in left auricle and equal in right auricle. In female (Nepalese and Indian): All parameters in Indian female were more as compared to Nepalese females.

\section{DISCUSSION}

Auricular height reaches its maturity level by the age of 12 years in female and 13 years in male ${ }^{7}$. Sexual dimorphism exists in dimensions of auricle were documented by Bozkir et al $^{8}$. In the study of Bozkir et $\mathrm{al}^{8}$, the height of left ear was $63.1 \mathrm{~mm}$, in men and 59.7 in female. Brucker MJ et al ${ }^{6}$ in their morphometric study of age and sex differences from auricular 


\begin{tabular}{|l|c|c|c|c|}
\hline & Nepalese & Nepalese & Indian & Indian \\
\cline { 2 - 5 } & Mean & SD & Mean & SD \\
\hline Right auricular height & 61.35 & 3.62 & 63.23 & 4.43 \\
\hline Left auricular height & 61.29 & 3.91 & 63.25 & 2.74 \\
\hline Right auricular width & 31.41 & 2.85 & 31.65 & 2.36 \\
\hline Left auricular width & 31.63 & 2.91 & 31.69 & 2.77 \\
\hline Right lobular height & 15.81 & 2.35 & 17.23 & 2.77 \\
\hline Left lobular height & 15.81 & 2.36 & 17.11 & 2.70 \\
\hline Right lobular width & 17.04 & 3.03 & 17.60 & 3.00 \\
\hline Left lobular width & 17.51 & 3.05 & 18.11 & \\
\hline
\end{tabular}

Table I: Comparison of auricle measurement in male (Nepalese and Indian)

\begin{tabular}{|l|c|c|c|c|}
\hline & Nepalese & Nepalese & Indian & Indian \\
\cline { 2 - 5 } & Mean & SD & Mean & 3.70 \\
\hline Right auricular height & 57.23 & 3.59 & 60.23 & 3.95 \\
\hline Left auricular height & 57.56 & 3.81 & 60.19 & 2.20 \\
\hline Right auricular width & 28.19 & 3.03 & 30.69 & 2.34 \\
\hline Left auricular width & 28.76 & 3.11 & 31.69 & 2.51 \\
\hline Right lobular height & 16.06 & 2.83 & 16.61 & 2.48 \\
\hline Left lobular height & 15.86 & 2.20 & 16.46 & 2.00 \\
\hline Right lobular width & 16.08 & 2.56 & 17.19 & 2.12 \\
\hline Left lobular width & 16.15 & 2.47 & 17.76 & \\
\hline
\end{tabular}

Table II: Comparison of auricle measurement in female (Nepalese and Indian)

height of 63.0. In our study the auricular height in Indian male 63.2 (right and left) and female $60.2 \mathrm{in} \mathrm{right,} 60.1 \mathrm{in} \mathrm{left.}$

As per K.Skaria Alexander et al ${ }^{3}$ the measurement of auricular height and width were higher as compare to our study. In our study there was sexual dimorphism in both Indian and Nepalese students of both sexes with regard to auricular height. Measurements in Nepalese student were less as compared to Indian.

The differences in male and female may be linked to the statement that auricular expansion starts early in males than in females which is continuous upto old age?

Sidra Shireen et $\mathrm{al}^{10}$ observed that all parameters are significantly larger in male than in female on both sides. Total auricular height and width were significantly greater. These results are similar to the present study.

Observations by D.Deopa et al ${ }^{11}$ are lesser for all parameters in Indian female, but for Nepalese they are similar.

\section{CONCLUSION}

Present study provides mean value of different Anthropometric parameter in both sexes and nationals of two different country. From this study following conclusion can be made:
- All auricle measurements are greater in Indian than in Nepalese.

- Sexual dimorphism was observed in both groups, that is measurement in male were greater than in female.

However for more conclusive result the study should be undertaken on large scale.

\section{REFERENCES}

1. Williams PL, Dyson M, editors. Gray's Anatomy. $37^{\text {th }}$ ed. London: ELBS Churchill Livingstone. 1989.p.1219-20.

2. https://www.pasps.org/otoplasty.htm

3. Alexander KS, Stott DJ, Sivakumar B, Kang N. A morphometric study of the human ear. Journal of Plastic, Reconstructive and Aesthetic Surgery. 2011;64:41-47.

4. De Carlo D, Metaxas D, Stone M. An Anthropometric face model using variational techniques. Proceeding of the $25^{\text {th }}$ Annual Conference Graphics and Interactive Techniques, New York: ACM, 1998;67-74.

5. McKinney P, Giese S, Placik O. Management of the ear in rhytidectomy. Plast Reconstr Surg. 1993; 92:858-66.

6. Brucker MJ, Patel J, Sullivan PK. A morphometric study of the external ear: Age and sex related differences. Plast Reconstr Surg. 2003;112:647-52.

7. Ito I, Imada M. A morphological study of age changes in adult human auricular cartilage with special emphasis on elastic fibers. Laryngoscope. 2001;111:881-6. 
8. Bozkir MG, Karakas P, Yavuz M, Dere F. Morphometry of the external ear in our adult population. Aesth Plast Surg. 2006;30:81-85.

9. Taura M. G. External ear anthropometry among Hausas of Nigeria; the search of sexual dimorphismand correlations. World J Med Med Sci Res. 2013; 1(5): 091-5.

10. Shireen S, Karadkhelkar VP. Anthropometric measurement of human external ear. J of Evolution of Med and Dent Sci 2015; 4(59): 10333-8.

11. Deopa D, Thakkar H, Prakash C, Niranjan R, Barua M. Anthropometric measurements of external ear of medical students in Uttarakhand Region. J Anat Soc India. 2013;62:79-83. 